\title{
Why Talking About Well-Being at School
}

\author{
PhD. Cand. Enkeleda Stefa, \\ European University of Tirana,
}

Albania

\begin{abstract}
Education has not only the role of offering students didactic knowledge but it also has the major role to educate the young generation towards their well-being and personal growth. The school is a place where children spend a considerable part of their time and get knowledge and learn to know themselves and those around them. So then is the duty of the school to take care of children and adolescents, to grow responsible person who will be active citizens in this global world. There are precisely the experiences in the school those who affect mostly in the future of the individual. A rapid intervention, starting in the early years, represents the most accurate means to develop among the new generation the attention towards the factors on which the individual and collective well-being depends on. Schools should be repositioned because it is no longer just a place of learning, with complete reference to the materials and curricular disciplines. Education has a responsibility to treat all areas containing personal life, emotional, intellectual, social, cultural and moral. School should assure students a professional training model to provide safe and existential horizons and worth directions. The educational and formative act of the school is very essential in favor of taking and putting into practice those knowledge and competencies that can lead to lifestyles oriented toward the well-being and the prevention of deviant behavior. The school's success in promoting psychological well-being of students lies in the fact that it will decide on the most part in the future success of our society.
\end{abstract}

Keywords: promoting well-being, supportive school, children, adolescents, empowerment.

\section{Introduction}

School is an important element of socialization after the family, where there are defined and constructed levels of identity and self-assessments, interactive and social behavior and skills. Its educational objectives do not end with educational and didactic aspects, but also in the formation and human aspects. So, if the family is the first place that protects and enhances the complex capabilities of individual development, in a context of psychological well-being the school should be part of the same process, with specific ways and objectives (Vergara, 2001).

For the first time the report of the Organization for Economic Cooperation and Development (OECD) "Education at a Glance 2009: OECD Indicators" conducted a survey on the impact of educational factors on the health aspects, interest in politics and the belief among the people, from whom it shows that students who have completed higher education enjoy better health and have higher confidence in themselves than others and a more growing political interest. So, what individuals benefit through education plays an important role in economic growth and personal benefits (Organisation for Economic Cooperation and Development, 2009).

Education, on the one hand is considered as a sustainable source for the growth and well-being of every individual and on the other hand as one of the main conditions for economic, social and cultural development, even the exercise of authentic democracy. A good education should allow everyone to be autonomous and to be good citizens as well as to be able to find spaces so that they can be integrated into society and have a job in the future (Braibanti P., 2005).

School shares this educational role with the family and if in the family there are structured the first models of proper behavior, the school should consolidate and protect them from deviant stimuli. The educational and formative act of the school is very essential in favor of taking and putting into practice those knowledge and competencies that can lead to lifestyles oriented toward the well-being and the prevention of deviant behavior. It is obvious that firstly it should be formed the 
determination of the individual in order to define at each of them an inner and steady trend so that they can make conscious choices about their own well-being. We should thus prepare an educational line that, through knowledge (knowing) causes behavior (knowing how to do) coherent with a life model oriented to the general well-being of the individual (knowing how to be).

The vision for the world, ways of approaching to problem solving, lifestyles that an individual adopt in adulthood find their matrix in the diversity of experiences made in the development period, attitudes and behaviors that at that stage of rapid growth of life are structured more sustainably in his personality. A rapid intervention, starting in the early years, represents the most accurate means to develop among the new generation the attention towards the factors on which the individual and collective well-being depends on. The family and then the school cannot leave behind, between their educational duties, this area of child training; it cannot be said "to know how to be" if the psychic dimension is not integrated with the physical one, if to the well-being of the mind and soul is not constantly attached that of the body (Barbieri R., 2004).

Among the topics of particular importance to the promotion of the well-being in schools must be remembered: nutrition, physical exercise, tobacco-smoking among adolescents, use of alcohol and other substances, sexuality, communication skills, ability to solve problems and self-esteem.

An extensive study conducted by the National Consortium for Humanizing Education, has shown that students whose teachers were qualified on empathic listening, on direct messages and on conflict resolution skills, have achieved significant progress reaching the best points on standardized tests in math, language and literature. It is also noted a reduction of $30 \%$ of absenteeism compared with the period before the training of their teachers for effective teacher program Teacher Effectiveness Training (TET). From this study it was observed that these competences contribute positively in mental health and in the success in the educational field and there are many good reasons for an intervention with the target the students who are the components of a healthy school (Zucconi A., Howell P., 2003).

It has become necessary nowadays to fully intervene in schools for promoting the well-being and leave behind as soon as possible, the standardized approach, by fully paying attention to students' requests and aiming the realization of a "school that suits students". The school contributes to the construction of identity definitions by selecting the self-assessment capabilities, interactive and social skills, and acquiring the necessary skills in order to be functional in the adaptation and integration process (Barisone M., 2002).

Schools should be repositioned because it is no longer just a place of learning, with complete reference to the materials and curricular disciplines. Education has a responsibility to treat all areas containing personal life, emotional, intellectual, social, cultural and moral.

School should assure students a professional training model to provide safe and existential horizons and worth directions. It should begin an institutional and cultural innovation season, pay close attention to students' heart, to provide scientific perseverance in its teaching/learning path, to have teachers with a rich professional wardrobe. Schools should also function as a curative clinic to reduce the unacceptable numbers of unjustified dispersion, from which the educational system suffers. This perdition is like a prism with three shapes: one is material, one is intellectual and the other is relationships.

Firstly, to heal the school from the pathology of material dispersion - generated by failing and dropouts - means to guarantee to all the students the right of entering and coming out of the non-mandatory classes.

Secondly, to heal the school from the pathology of intellectual dispersion it means to eliminate the gap (space) which lies between teaching and learning: between what teachers explain and what students absorbs.

Thirdly, to heal the school from the pathology of dispersion of relations (generated by introducing the climate of competition and aggressiveness into the schools) means to transform it into a vitality of human relations, into an environment overflowing with coexistence, dialogue, friendship and cooperation. So, in a setting equipped with figures of flexibility and regularity: anti-authoritarian and non-managerial. To combat the dispersion of interpersonal relations schools are invited to provide their teaching environments and didactic times as "the meeting point" either with varied socialization forms (collecting - distribution - recollecting), or with ethical value intense event filled with listening, loyalty, responsibility, solidarity. The most effective antidote to the dispersion of relations is called cooperation (Frabboni, 2006).

School can interfere with a clear intention of the psychological component of the person, either by promoting a healthy balance between the individual components while staying in it, or by facilitating the promotion of specific factors relating to 
the stressful events of the future life of the individual. From the age of school and onwards exploratory activity increases, and the child sees the school as a privileged location for exploration. Here the child and later the teenager experiment, for a considerable time (about 8 hours per day), their knowledge, their behavior schemes for interpersonal relations capabilities, facing not only with those of their peers, but also with teachers who care for their growth. It is very important that school assume responsibly and official the dimension of the relations and the affective educational process even before his closely associated with learning. With the "dimension of relations" in the process of teaching/learning we understand socioaffective contact between teachers and students. So in terms of promoting schools can and should provide an opportunity to strengthen self-esteem, an appropriate and loving self image, effective social skills and relationships, factors that are considered too protective of stressful life events later (Vergara, 2001).

Promoting psychological well-being to anyone who is part of the school community can be understood as a learning process which promotes a sense of belonging, competence and autonomy. Promoting psychological well-being in school can be seen as an active and collaborative process in which the relationship between individuals and the surrounding environment is continuously building and modified. Experiences that members of the school have regulate learning in many aspects such as it may affect the ability to focus and observe the environment, to change and interpret the obtained results. Feelings of involvement and empowerment of students during the studies are regulated by the experiences they have in relationships with peers and teachers, belonging in the same class and school, self-effectiveness and control that they have towards the actions of the others. Promoting psychological well-being does not only provide learning knowledge and skills, but a continuation, an interactive development process in which the motives and feelings play an important role. The experiencing of the pedagogical well-being cannot promote or achieve educational goals, but certainly serves as a guide to the achievement of learning outcomes. Well-being of children in school is part of the overall well-being of the children along with other important elements such as health, social circle outside the school, especially the relationship with parents, other relatives and friends. Students can experience empowerment, joy and satisfaction during interaction with peers as well as feelings of anxiety and stress caused by problems with the lessons. In some cases the well-being in school can lead to interactions with peers and teachers, and even can affect the mitigation of problems and anxieties caused by the unresolved family event. So well-being in school can be seen as a key aspect to cope with the flexibility of the students, the development stages and to overcome them during school (Pyhältö K., 2010).

The task of the teachers in the school who promote well-being is multiple and extremely important because except learning concepts and traditional basic knowledge they must show care and give students an emotional support as well as direct them, by creating a supportive learning environment and interacting with regional organizations, thus formally and informally guiding them and modeling their behavior. Teachers' efforts in motivating and involving children in learning are considered equally important to the efforts to transmit the curricular content. The teacher's role as the carrier of knowledge has opened the way for active learning approach, an education which aims the student, where numerous roles are considered more effective to facilitate learning. The role of teachers as health education carrier, has led to almost an exclusion of previous complementary roles in education. The role of teachers in the implementation of interventions that promote well-being in school is estimated using precise measuring. Teachers have a responsibility to create a supportive school environment and they are encouraged to integrate wider objectives in their learning mode.

In a study conducted in Kahnawake, Montreal, Canada, in 2003, to understand the role of teachers in the implementation of the objectives for the prevention of diabetes at school, it was observed that their role was essential. In teaching health education curricula teachers were inclined to describe how they adapted the curricula according to local circumstances in which they lived. Attention was focused on the role played by teachers in encouraging pupils towards healthy eating and physical exercise by firstly changing themselves, so as to become an example to the students. This strategy of the teachers to start it themselves and their modeling role was also attached to a high level of motivation to implement the program objectives. It has earlier confirmed that children learn mainly by observing others' behavior. School thus has the task not only to transmit the information, but also to contribute to a broader education that can be summarized efficiently in forming a personal and social identity (Cargo M., 2006).

Although schools in developing countries like ours deal with issues such as the basics of hygiene, the importance of physical exercise, issues related to sexually transmitted diseases, yet they are far from being called a school that promotes health. In recent years it is considerably being discussed learning with the targeting students, for critical learning or issues related to bullying, the use of prohibited substances and smoking, but still does not have a program that will encourage students to develop skills to make them healthy consumer. Besides basic knowledge in the fields of nutrition, oral health, sexuality, 
relationships and drugs, the majority of the programs that promote well-being aim to achieve results in improving personal skills in problem solving, communication and decision-making .

Schools and the education system in general are beginning to recognize the mutual relationship between poor health and low achievements in education, and have embraced school approach that promotes well-being to maximize educational and academic achievement. St Leger and Nutbeam have proposed that schools that promote well-being, contribute to four major achievements: 1) to lifelong learning; 2) skills and behavior; 3) knowledge and specific data; 4) personal qualities. Schools which are open towards the way they are directed, the way they seek to increase educational outcomes for their students, how they foster relationships between students and school staff provide an excellent environment for strengthening of empowerment and achieving a high level of critical learning (St Leger, 2001).

Generally interventions made for health promotion in schools are interventions that are added to the curriculum and not in the context of a proper curriculum, therefore the impact that they have as students as well as teachers is not continuous. This brings a fractional interest by teachers and a sporadic and superficial motivation from students. Often they are implemented as pilot projects and the desire of a few teachers, and as such are not spanning the curriculum. Even these interventions generate results that fail to demonstrate their effectiveness.

This leads to the impression that schools that promote health and well-being realize weak programs, low efficiency, difficulties in developing an effective opinion on the self-forming process, observing strong points and critical points of intervention, waiting for an official implementation of these interventions, and to document and reproduce them (Sun J., 2007).

Schools play a key role in promoting health and well-being and should take advantage of this opportunity to contribute in building the future of the society by developing programs which promote physical and mental health and in this way the schools themselves become healthy. Schools have a unique opportunity to intervene to children in a moment in which critical learning happens which will influence in their habits and their health throughout life. Systematic introduction into curriculums containing basic concepts of health and its promotion is delayed while it is an essential element to equip children with the necessary empowerment to have healthy lifestyles and to contribute to social change from which depends the progress of well-being (Zucconi A., Howell P., 2003).

The school's success in educating students lies in the fact that it will decide on the most part in the future success of our society. It is essential that citizens shall become part of the decision about how schools should operate (Forman S.G., 1997).

\section{References}

[1] Barbieri R., B. A. (2004). Linee guida per un corretto stile di vita. Retrieved from https://archivio.pubblica.istruzione.it/essere_benessere/allegati/linee_guida.pdf

[2] Barisone M., G. L. (2002). Strumenti e spazi organizzativi per la produzione di benessere nella scuola. Psicologia e lavoro, Vol. 32, 35-39.

[3] Braibanti P., Z. A. (2005). Lo Sguardo Di Igea: Soggetti, contesti e azioni di psicologia della salute. Milano: Franco Angeli.

[4] Cargo M., S. J. (2006). Understanding the social context of school health promotion program implementation. Health Education, Vol.106(2), 85-97.(n.d.).

[5] Forman S.G., W. L. (1997). Educational Policy Through Service Learning: Preparation for Citizenship and Civic Participation. Civic Engagement, 26.

[6] Frabboni. (2006). La scuola che verrà. Trento: Erickson.

[7] Organisation for Economic Cooperation and Development. (2009). Education at a Glance 2009: OECD Indicators. http://www.oecd.org/education/skills-beyond-school/43636332.pdf.

[8] Pyhältö K., S. T. (2010). Pupils'pedagogical well-being in comprehensive school- significant positive and negative school experiences of Finnish ninth graders. European Journal Psychology of Education, Vol.25, 207-221.

[9] St Leger. (2001). Schools, health literacy and public health: possibilities and challenges. Health promotion international, Vol.16(2), 197-205. 
[10] Sun J., S. D. (2007). How effective is the health-promoting school approach in building social capital in primary schools? Health Education, Vol.107(6), 556-574.

[11] Vergara, F. C. (2001). La promozione del benessere nella famiglia, nella scuola e nei servizi. Milano: Franco Angeli.

[12] Zucconi A., Howell P. (2003). La promozione della salute. Un approccio globale per il benessere della persona e della società. Molfetta: La Meridiana. 